EDITORIAL

\title{
Primer Congreso Chileno de Salud Pública Marcando la Senda
}

Más de 400 personas provenientes tanto de Chile como de otros países latinoamericanos, se dieron cita el pasado mes de julio en el Primer Congreso Chileno de Salud Pública, bajo el slogan "La salud en el siglo XXI: perspectivas y desafíos". Al concebir este evento nos planteamos dos objetivos: generar un espacio interdisciplinario para la presentación de las más recientes investigaciones y experiencias en salud pública, que constituyan un aporte a la solución de los problemas de salud que plantea el presente siglo; y constituir una plataforma propicia para el debate de los temas de punta -actuales y futuros- a nivel nacional y global.

Ambos propósitos fueron logrados en plenitud, consolidándose además una histórica alianza entre instituciones públicas y privadas convocadas por la Escuela de Salud Pública de la Universidad de Chile, el Ministerio de Salud y la Organización Panamericana de la Salud. Junto a las universidades Católica de Chile, de Concepción y Andrés Bello; Isapres de Chile; Conicyt y las dos asociaciones de clínicas privadas existentes en el país, se hizo evidente el compromiso por contribuir eficazmente a la protección y mejoramiento de la salud de las personas, las comunidades y su entorno.

La presencia de altas autoridades, encabezadas por la Presidenta de la República -quien nos entregó un significativo y visionario mensaje-, así como de conferencistas y panelistas de renombre internacional, validó el esfuerzo realizado. Asimismo, constituyó una valiosa oportunidad para conocer los éxitos, las experiencias y los puntos de vista de quienes, desde distintos ámbitos, aportan al desarrollo de la salud pública, pilar fundamental en el desarrollo social de los países.

Diez cursos precongreso, más de 400 trabajos recibidos entre los cuales se seleccionaron 291, un Comité Científico formado por alrededor de 60 profesionales, dos conferencias magistrales, ocho mesas redondas y cuatro simposios satélite, dan cuenta de la parte visible del Congreso, pero sin duda, éste fue mucho más.

El Congreso dejó de manifiesto la responsabilidad que compete a todos los sectores, pero particularmente a las instituciones académicas, en el logro de los objetivos sanitarios vigentes en Chile. Frente a la reemergencia del paradigma que valora los factores sociales y estructurales como determinantes del nivel de vida y condiciones de salud de los individuos y las poblaciones, así como frente a una situación epidemiológica en que predominan las afecciones crónicas no trasmisibles y los riesgos de naturaleza psicosocial, nuestro país prioriza en sus políticas el logro de una efectiva protección social y de salud. Sin embargo, para alcanzar estas metas se requiere fortalecer nuestro capital social, concretar la intersectorialidad y crear efectivos vínculos con la comunidad.

A las instituciones académicas nos corresponde, junto con reconocer esta realidad, aportar lo mejor de nuestro quehacer a su éxito, comprometiéndonos a ser creativas y a impulsar con fuerza el desarrollo científico en este campo, incluyendo la formación de profesionales de excelencia. En este aspecto, la investigación en salud pública es un quehacer clave, el cual, a pesar de los avances realizados en los últimos años, sigue siendo débil. Ello se debe, en parte, a que muchos no tienen conciencia sobre la necesidad de contar con recursos y mecanismos más potentes para su desarrollo en la agenda de investigación científica y tecnológica de nuestro país y, en parte también, a que la salud pública no tiene el reconocimiento que se merece en nuestras comunidades académicas.

A este respecto, la Presidenta Bachelet nos entregó en el discurso inaugural algunos mensajes que permiten ser optimistas. En primer término, destacó que se haya generado este encuentro entre 
profesionales y académicos que han hecho de la salud pública el centro de su quehacer. "Ustedes están anticipando el futuro y preparando a Chile para enfrentarlo de la mejor manera posible", manifestó la mandataria, instándonos a buscar nuevas formas de abordar los grandes temas de la salud pública nacional.

Asimismo, se refirió a la necesidad de invertir fuertemente en investigación científica y tecnológica del más alto nivel e hizo explícito su compromiso de elevar el porcentaje del PIB destinado a esta actividad. A la vez, subrayó la importancia de establecer una verdadera alianza público-privada en pos de un mayor y más efectivo desarrollo en este ámbito.

En suma, el Primer Congreso Chileno de Salud Pública nos dejó varias enseñanzas. Entre ellas, que en el país existe una creciente demanda por mayor conocimiento, mejor investigación y programas que permitan optimizar la salud de la población chilena en su conjunto. También, luego de escuchar los estudios presentados, podemos sentirnos orgullosos de contar con profesionales de las más diversas áreas, de distintas generaciones e inmersos en realidades diferentes, fuertemente motivados y comprometidos con el objetivo común de hacer de Chile un país con condiciones de salud y calidad de vida de primer nivel. Otro legado del Congreso fue la certeza de que los sectores público, privado, académico e internacional pueden trabajar unidos y potenciarse para generar iniciativas sustentables de beneficio y alcance nacional.

Tenemos, entonces, la gran tarea de seguir avanzando por una senda que esperamos este Congreso haya contribuido a señalar.

Giorgio Solimano

Director 